\title{
Biomechanical Analysis of Grafted and Nongrafted Maxillary Sinus Augmentation in the Atrophic Posterior Maxilla with Three- Dimensional Finite Element Method
}

\author{
Xuan Wang, ${ }^{1,2}$ Tianqi Zhang, ${ }^{1,2}$ Enli Yang, 1,2 Zhiyuan Gong, ${ }^{1,2}$ Hongzhou Shen, ${ }^{1,2}$ \\ Haiwei $W u\left(D,{ }^{1,2}\right.$ and Dongsheng Zhang $\mathbb{B}^{1,2}$ \\ ${ }^{1}$ Department of Oral and Maxillofacial Surgery, Shandong Provincial Hospital Affiliated to Shandong First Medical University, \\ Jinan, China \\ ${ }^{2}$ Department of Oral and Maxillofacial Surgery, Shandong Provincial Hospital Affiliated to Shandong University, Jinan, China \\ Correspondence should be addressed to Haiwei Wu; hewty@qq.com and Dongsheng Zhang; ds63zhang@sdu.edu.cn
}

Received 6 August 2020; Revised 18 September 2020; Accepted 18 September 2020; Published 5 October 2020

Academic Editor: Guanghai Jin

Copyright (c) 2020 Xuan Wang et al. This is an open access article distributed under the Creative Commons Attribution License, which permits unrestricted use, distribution, and reproduction in any medium, provided the original work is properly cited.

\begin{abstract}
This study is aimed at determining the optimal sinus augmentation approach considering the poor bone condition in the zone of atrophic posterior maxilla. A series of simplified maxillary segment models varying in residual bone height (RBH) and bone quality were established. A $10 \mathrm{~mm}$ standard implant combined with two types of maxillary sinus augmentation methods was applied with the $\mathrm{RBH}$, which was less than $10 \mathrm{~mm}$ in the maxilla. The maximal equivalent von Mises (EQV) stress in residual bone was evaluated. Bone quality had an enormous impact on the stress magnitude of supporting bone. Applying sinus augmentation combined with grafts was suitable for stress distribution, and high-stiffness graft performed better than low-stiffness one. For $7 \mathrm{~mm}$ and $5 \mathrm{~mm}$ atrophic maxilla, nongrafted maxillary sinus augmentation was feasible in D3 bone. Poor bone quality was a negative factor for the implant in the region of atrophic posterior maxilla, which could be improved by grafts. Meanwhile, the choice of maxillary sinus augmentation approaches should be determined by the RBH and quality.
\end{abstract}

\section{Introduction}

Implant restoration is an effective means to restore the configuration and function of missing teeth. Previous studies have demonstrated a high success rate for this kind of therapy, confirming the merits of dental implant treatment [1]. As a load-bearing device, the dental implant needs to sustain the occlusal force and transfer load to the supporting bone, as was determined by the volume of residual bone $[2,3]$. In clinical practice, edentulous patients with progressive alveolar bone resorption or adjacent crucial anatomical structure, such as maxillary sinus, make the provision of the implant with optimal dimensions an arduous task [4].

To address this, maxillary sinus augmentation is a predictable surgical method that increases the volume of the available bone $[5,6]$ and was developed to optimize alveolar bone configuration in the region of the posterior maxilla. Generally, maxillary sinus augmentation can be classified into two types: one is in combination with utilizing graft in maxillary sinus augmentation and the other one is merely treated with maxillary sinus augmentation without using any grafts. Sinus floor augmentation with subsequent graft materials embedding has been attested to be an effective technique for correcting bone deficits by a series of clinical evidence [7]. A wide variety of graft materials are available for restoring the resorbed bone, including autologous bone, alloplasts, xenografts, allografts, or a combination of these [8]. The ideal one could improve bone biomechanical effects to a significant extent. However, the necessity of placing the graft in augmented sinus has been questioned recently [911]. Palma et al. [12] declared that with the newly created space following sinus floor augmentation maintaining, the blood clot inside could gain bone formation. A recent systematic review declared that there were no significant differences in the short-time success rate of implant placement between grafted and non-grafted sinus augmentation [13]. 
Though sinus augmentation has been a commonly applied technique, the choice of sinus augmentation approaches when encountering the atrophic maxilla possessing poor bone quality needs to be further validated.

Available residual bone was particularly crucial in implant placement, described in terms of bone quality and quantity to reflect the bone biomechanical property. Bone quality was related to bone tissue elasticity and mechanical strength, which subsequently determined implant selection and surgical means [14]. The supporting bone possessing high density could not only provide better mechanical stabilization but also permit even stress distribution in the boneimplant interface [15]. However, weak bone quantity or quality was commonly encountered in the region of posterior maxilla, which led to a higher occurrence of failure compared with other regions. In particular, the lower density of trabecular bone can easily reduce the stability of the implant and increase bone stress $[15,16]$.

At present, the three-dimensional finite element (3-D FE) analysis has been widely used to study the mechanical behavior of implant-related structures and surrounding bone tissue. With the recent advances in this technology, it is possible to simulate complex structures on a microscopic scale to observe further stress distribution that is clinically impossible to observe, to analyze the relevant stresses in the internal structure of the model, and to assess the associated risks [17-19]. The problem of choosing sinus augmentation approaches based on actual bone quality and residual bone volume is of great importance in dental implantation. The 3-D FE analysis was adopted in this study to verify the ultimate magnitude of bone stress in an intricate system of bone tissue. The biomechanical effects of different sinus augmentation methods are examined in a maxilla possessing various strength characteristics. The study is aimed at determining the optimal sinus augmentation method based on the condition of the supporting bone.

\section{Materials and Methods}

2.1. FE Models. Model a series of simplified maxillary segment models with Creo 2.0 (PTC software, USA). Attempting to simulate the atrophic posterior maxilla, the maxillary models were classified into two types of bone quality, D3 and D4 bone according to Lekholm et al. [20]. Despite the difference in the density of trabecular bone, they both possessed the same configuration and structure. The simplified maxillary segment consisted of thin cortical bone surrounding trabecular bone. The thickness of cortical bone was $0.5 \mathrm{~mm}$ in the sinus site and $1 \mathrm{~mm}$ in the crestal site. These models have different RBHs. The overall dimension of this segment was $10 \mathrm{~mm}$ in mesiodistal length and buccolingual width and $14 \mathrm{~mm}$ in height. All maxillary segment models were divided into 4 groups based on the RBH: $3 \mathrm{~mm}, 5 \mathrm{~mm}$, $7 \mathrm{~mm}$, and $10 \mathrm{~mm}$ (Figure 1). For groups with less than $10 \mathrm{~mm} \mathrm{RBH}$, the biomechanical effects of grafted and nongrafted maxillary sinus augmentation were investigated. Graft in maxillary sinus was presumed fully peri-implant packing for simulating an ideal situation suggested by Tepper et al. [21]. A titanium implant model (Neo CMI implant, IS
410, Neo Biotech, Korea) was the same as the original mechanical drawing measured with a vernier caliper. The major diameter of the standard implant was $4.0 \mathrm{~mm}$; the total length was $10 \mathrm{~mm}$ (Figure 2).

All 3D solid models were input into a FE software (Ansys Workbench 14.5, SAS IP, Canonsburg, PA) designed to generate and analyze discrete FE meshes. All finite element models were generated from means of tetrahedral elements, and refinement was used to the bone-implant interface of interest to ensure the accuracy of results (Figure 3). Stress distribution in supporting bone was assessed by the maximal EQV stress, which was reported to be a credible parameter for evaluating bone failure risk $[16,22]$.

2.2. Material Properties. In this study, materials were linearly elastic and isotropic, and all materials' volume is considered to be homogenous. Implants were supposed to be made of titanium alloy Ti6Al4V. Table 1 lists the corresponding modulus of elasticity and Poisson's ratio for all materials [19, 23, 24]. The high-dense trabecular bone's (D3 bone) elastic modulus was $1.37 \mathrm{GPa}$, and low-dense trabecular bone (D4 bone) was $0.231 \mathrm{GPa}$. Two distinct grafts were assigned to represent a wide spectrum of stiffness. The higher one is closer to the cortical bone, and the lower one is lower than the stiffness of the high stiffness trabecular bone.

2.3. Boundary Conditions and Loading. The exterior nodes on the maxillary segment's mesial and distal surfaces were constrained to no displacement as boundary conditions for each model. A fixed bond was prescribed between the rough implant surface and surrounding bone for simulating the biomechanical environment. A $150 \mathrm{~N}$ oblique force was applied to the implant at an angle of approximately $60^{\circ}$ to the implant's occlusal surface, as shown in Figure 3[24-26]. The loading force was static and was calculated by EQV stress.

\section{Results}

The stress distribution contour map showed that stress concentration was mainly located in the cortical bone around the implant's cervical portion, irrespective of bone condition (Figure 4). Comparative analysis of D3 and D4 bone stresses shows that bone quality has a huge impact on the stress distribution of supporting bone (Figure 5). It was clear that with the reduction of $\mathrm{RBH}$, stress magnitude in $\mathrm{D} 4$ bone was markedly higher than D3 bone. The gap tended to enlarge following the aggravation of residual bone resorption.

When $\mathrm{RBH}$ was $10 \mathrm{~mm}$, residual bone volume was just suitable for the standard implant. The maximal EQV stress was $22.94 \mathrm{MPa}$ in $\mathrm{D} 3$ bone and $39.32 \mathrm{MPa}$ in D4 bone. The maximum EQV stress values of the remaining groups were shown in Table 2 . When $\mathrm{RBH}$ was resorbed to $7 \mathrm{~mm}$, there was only a slight increase in stress values. Applying a lowstiffness graft under this circumstance seemed to do no apparent help for improving stress distribution. On the contrary, the high-stiffness group decreased stress value by nearly $31.6 \%$ in D3 bone and $52.2 \%$ in D4 bone (Figure 6(a)). When $\mathrm{RBH}$ reduced to $5 \mathrm{~mm}$, a rapidly 

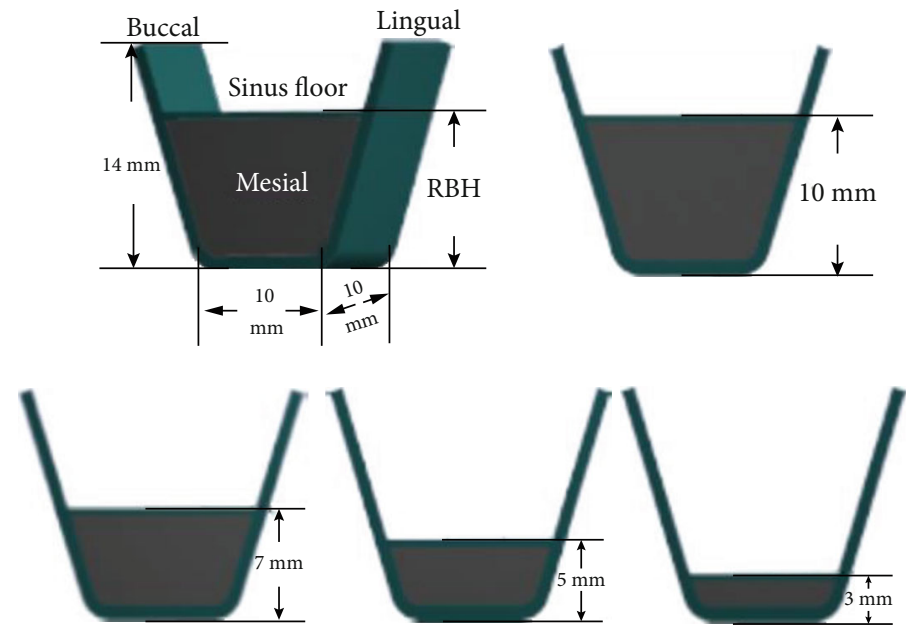

Figure 1: Simplified maxillary segment model. The buccolingual and mesiodistal distance was $10 \mathrm{~mm}$; the overall height was $14 \mathrm{~mm}$. The maxillary models were classified into 4 groups by RBH: $3 \mathrm{~mm}, 5 \mathrm{~mm}, 7 \mathrm{~mm}$, and $10 \mathrm{~mm}$.

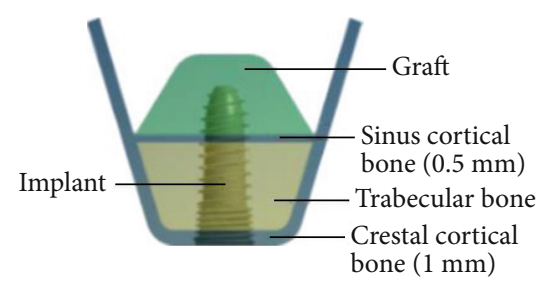

(a)

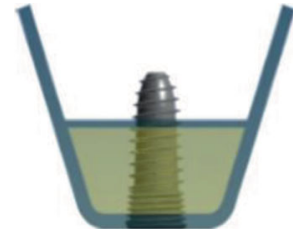

(b)

FIgURE 2: Two types of maxillary sinus augmentation approaches. (a) Grafted sinus augmentation: the apical portion of the implant was totally embedded into the graft; (b) Nongrafted sinus augmentation.

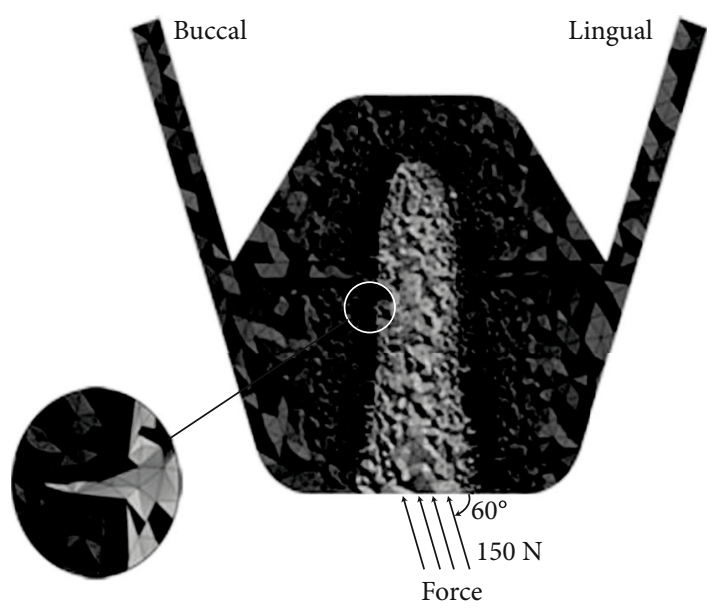

Figure 3: Cross-sectional views of the symmetry plane in the meshed model. A $150 \mathrm{~N}$ oblique force was applied to the implant at an angle of approximately $60^{\circ}$ to the occlusal surface of the implant.

increasing stage of EQV stress emerged. Taking bone quality into account, the stress level in D3 bone with $5 \mathrm{~mm} \mathrm{RBH}$ was close to that in D4 bone with $10 \mathrm{~mm} \mathrm{RBH}$. Nevertheless, the stress level of D3 bone with $3 \mathrm{~mm} \mathrm{RBH}$ is lower than that of D4 bone with $5 \mathrm{~mm} \mathrm{RBH}$. Stress value dropped apparently with the help of low-stiffness graft. For the high-stiffness graft, the decreasing degree of stress value enlarged (Figure 6(b)). When $\mathrm{RBH}$ remained only $3 \mathrm{~mm}$, the residual bone was incapable of bearing load solely. The results confirmed this that stress value rose by $143.8 \%$ in D3 bone and $106.9 \%$ in D4 bone compared with $10 \mathrm{~mm}$ group, which was unsatisfactory and made employing graft indispensable. Herewith quite limited residual bone, even the low-stiffness graft could decrease stress value markedly and highstiffness one performed better (Figure 6(c)). Interestingly, despite the $\mathrm{RBH}$, high-stiffness graft always reduced stress magnitude to the optimal level lower than $10 \mathrm{~mm}$ group.

\section{Discussion}

Two kinds of complications occur to the dental implant, namely, mechanical and biological complications, related to adverse biomechanical effects [24]. The excessive load was considered one of the main adverse biomechanical effects contributing to damaging normal bone remodeling equilibrium [27]. Therefore, from the biomechanical point of view, efforts should be made to avoid the adverse biomechanical effects, especially for the atrophic posterior maxillary region. However, the biomechanical effects caused by loading conditions or surrounding bone conditions are challenging to explore by solely applying clinical approaches. With these in mind, FE analysis has been generally used as a complementary approach to study the biomechanical response in 
TABLE 1: Elastic properties of materials modeled.

\begin{tabular}{lcc}
\hline Material & $\begin{array}{c}\text { Young's modulus, } E \\
(\mathrm{GPa})\end{array}$ & $\begin{array}{c}\text { Poisson's } \\
\text { ration, } v\end{array}$ \\
\hline Cortical bone & 13.7 & 0.3 \\
Trabecular bone (D2 \& & 1.37 & 0.3 \\
D3) & 0.231 & 0.3 \\
Trabecular bone (D4) & 11 & 0.3 \\
High-stiffness graft & 0.5 & 0.3 \\
Low-stiffness graft & 110 & 0.35 \\
Titanium & &
\end{tabular}
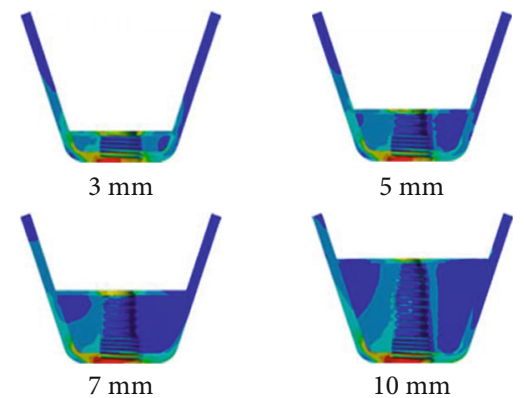

FIgURE 4: Stress distribution contour map in D3 bone adopting nongrafted sinus augmentation.

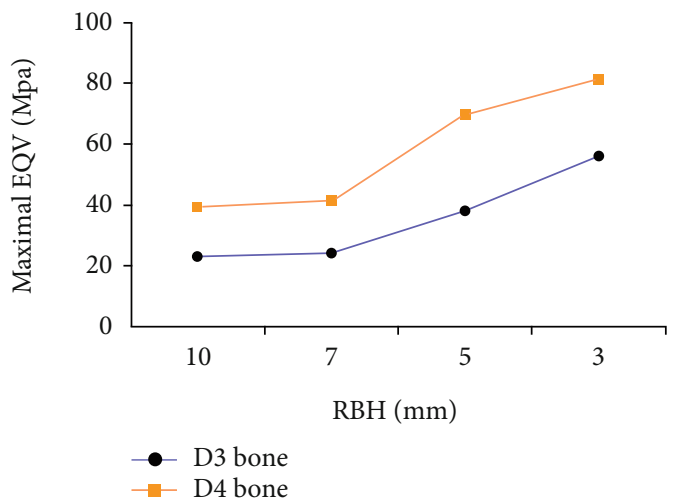

FIGURE 5: The magnitude of maximal EQV stress in D3 and D4 bone with nongrafted sinus augmentation.

TABLe 2: Maximal EQV stress (MPa) in supporting bone.

\begin{tabular}{lcccccc}
\hline \multirow{2}{*}{ RBH $(\mathrm{mm})$} & \multicolumn{2}{c}{ No graft } & \multicolumn{2}{c}{ Low-stiffness } & \multicolumn{2}{c}{ High-stiffness } \\
& Draft & D4 & D3 & D4 & D3 & D4 \\
\hline 7 & 24.237 & 41.268 & 23.657 & 40.737 & 16.567 & 19.739 \\
5 & 37.885 & 69.63 & 26.139 & 42.365 & 15.4 & 17.031 \\
3 & 55.927 & 81.358 & 29.288 & 51.583 & 14.066 & 16.482 \\
\hline
\end{tabular}

bone tissue. This study focused on the biomechanical effects caused by $\mathrm{RBH}$ and bone quality.

Notably, despite the changing variables, we observed that the highest overall stress was always concentrated in the implant neck's cortical bone. The same biomechanical behavior was also validated by a couple of prior studies [4,
28, 29]. Koca et al. suggested that the rigid connection between implant and bone accounted for this [2]. Furthermore, such a stress distribution pattern was one of the vital factors involving time-dependent marginal bone loss, inevitable progress jeopardizing implant stability after placement [30]. Marginal bone resorption usually begins in the cortical bone and progresses towards the apical direction. Van Steenberge et al. reported that marginal bone loss was as high as $0.4 \mathrm{~mm}$ in the first year after implant implantation, and in the next two years, the annual loss was reduced to $0.03 \mathrm{~mm}$ [31]. Hence, it seemed quite essential to diminish stress concentration in supporting bone.

Bone quality is proven to be one of the critical determinants for implant treatment planning [15]. Nevertheless, due to poor bone quality, the implant success rates in the posterior maxillary regions were lower than in other regions [32, 33]. In this case, an attempt was undertaken to investigate the impact of bone quality on the stress magnitude of supporting bone and emphasis on D3 and D4 bone. Although D4 bone possessed the same configuration as for D3 bone, D4 bone was comprised of lower-density trabecular bone inside, which distinguished from D3 bone. Correspondingly, higher stress was found to be located in D4 bone. Kumar demonstrated that the lower-density trabecular bone in D4 bone was incapable of withstanding high stress so that most of the stress was relocated to cortical bone [34]. This was verified by Chang's finding that the unfavorable stress distribution in D4 bone increased the risk of micromotion and instability of implant [24]. Considering the inability of altering the bone quality and consequent rising stress, it is more operable to modify the configuration of the atrophic maxilla to dissipate stress optimally.

Since the introduction of various materials, procedural modifications in the atrophic sinus region had been proposed to be efficient in optimizing stress distribution. As was shown in this study, graft in the maxillary sinus enhanced the loadbearing capacity of residual bone. However, the degree of enhancement mainly depended on its stiffness, which was fairly pertinent to the maturation process to a large extent [30]. The low-stiffness graft exhibited an obvious effect of reducing stress only in $5 \mathrm{~mm}$ and $3 \mathrm{~mm}$ groups. However, high-stiffness graft diminished stress concentration effectively regardless of different $\mathrm{RBH}$. This was presumably because the loading capacity of the low-stiffness graft was lower than that of high-stiffness one [35]. Therefore, special attention should be paid to the quality of the graft before the implant placement. Having higher stress in surrounding bone with low-stiffness graft embedded into the maxillary sinus would challenge the load-bearing capacity of supporting bone, especially for D4 bone. Additionally, decreasing the graft's stiffness would increase the micromotion in the bone-implant interface during the early stage of implant placement [30]. Hence in the biomechanical aspect, highstiffness graft might be a better choice for optimizing stress distribution.

Impaired bone height is frequently encountered when placing an implant in the zone of posterior maxilla. The crestal bone atrophy, together with sinus pneumatization in edentulous patients, prevented inserting the implant with 


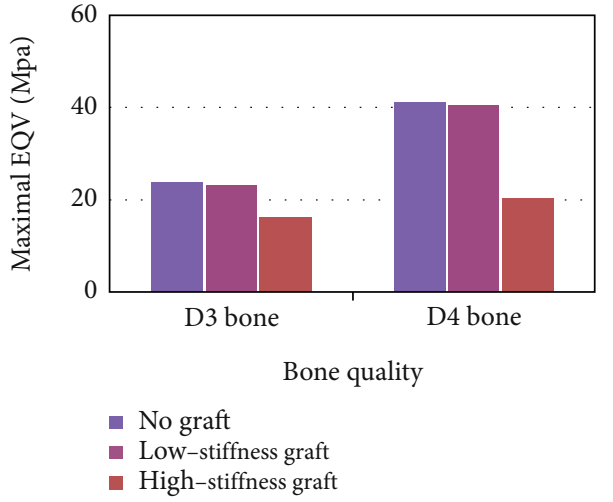

(a)

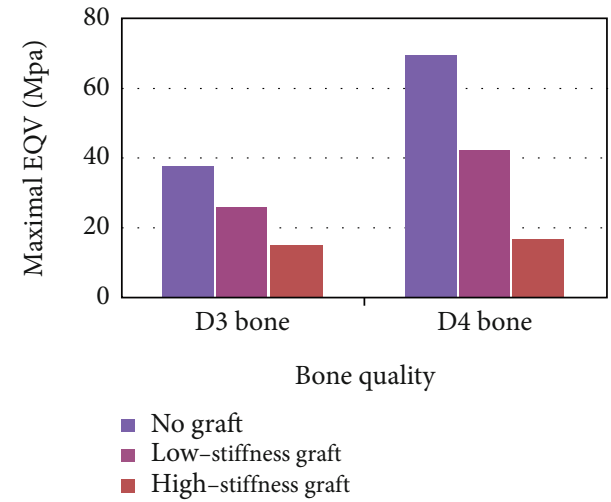

(b)

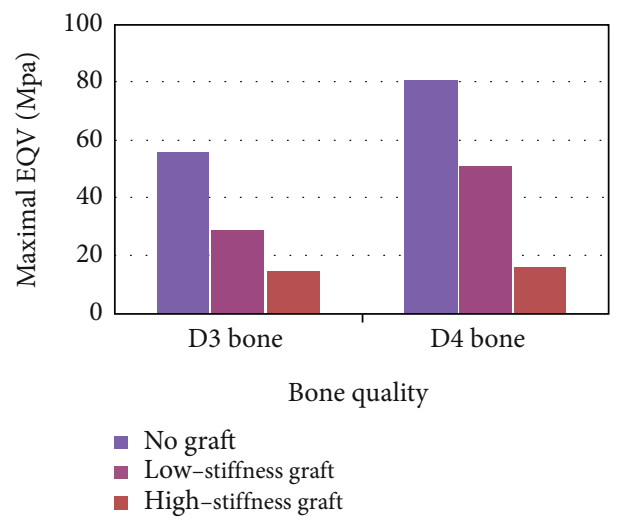

(c)

FIgURE 6: The maximal EQV stress induced by grafted and nongrafted sinus augmentation approaches: (a) $7 \mathrm{~mm} \mathrm{RBH}$; (b) $5 \mathrm{~mm}$ RBH; (c) $3 \mathrm{~mm} \mathrm{RBH.}$

an optimal dimension [36]. In order to improve residual bone volume, various surgical techniques and diverse graft materials have been put into use. RBH was the fundamental evaluation criterion determining the choice of sinus augmentation approaches before implant placement [37]. Clinically, when the $\mathrm{RBH}$ was above $10 \mathrm{~mm}$, a classic implant procedure was suggested. When the RBH was below 4-5 mm, a surgical approach involving graft materials through a lateral implant placement was recommended [38, 39]. For D3 bone, both two kinds of graft exhibited desirable stress dispersion effects, while stress magnitude in D4 bone was detrimental when applying low-stiffness graft. Consequently, to achieve better quality, sufficient healing duration of the graft was well recommended in the severely atrophic maxilla [35], particularly for D4 bone. Various surgical approaches would be indicated to guarantee implant stability with available $\mathrm{RBH}$ ranging from $5 \mathrm{~mm}$ to $10 \mathrm{~mm}$. Applying graft materials in sinus augmentation had already achieved affirmative results and become a requisite procedure to remedy alveolar bone deficiency before implant placement [40]. Nevertheless, with the accumulation of successful cases using nongraft sinus augmentation, a systematic review confirmed that the sinus augmentation method without applying any grafts was effective and safe [41]. Judging from the present study, although applying high-stiffness graft could diminish stress, the stress level in the $7 \mathrm{~mm}$ group had no significant change when com- paring with the $10 \mathrm{~mm}$ group. This might mean that the nongrafted sinus augmentation was relatively feasible in the slightly atrophic maxilla. When $\mathrm{RBH}$ was reduced to $5 \mathrm{~mm}$, stress appeared to rise markedly. Bruschi et al. [42] asserted that local treatment of the sinus augmentation without utilizing grafts was viable in the region of posterior maxilla, with as little as an $\mathrm{RBH}$ of $5 \mathrm{~mm}$. However, according to the present study, stress magnitude was comparatively acceptable only for D3 bone and it turned evidently unfavorable when bone quality deteriorated to D4 bone. For this reason, we speculated that this proposal only applied to maxilla with better bone quality. In general, with the help of grafts, including both low-stiffness and high-stiffness ones, bone stress returned to a tolerable level. Therefore, utilizing grafts to modify bone configuration seemed necessary for moderately atrophic maxilla with poor bone quality.

Because of its unique advantages in stress analysis, the 3D-FE method has been widely used in implant biomechanics research. In this article, we assumed a bond connection in the bone-implant interface. The 3D-FE analysis identified stress differences based on these possible treatment approaches for dental implants in the atrophic posterior maxilla, and the results could still partly demonstrate the biomechanical effects in the intricate biological tissues. However, the results of this study should be extended to the clinical situation. More clinically related models should be 
designed, and the improved shape of the maxilla will more closely simulate the actual situation for a more reliable FE analysis. Additionally, research is needed to correlate the stress and the response of actual bone tissue with predicted treatment outcomes, and as a way to improve implant design and treatment plans.

\section{Conclusion}

In our finite element study, conclusions can be drawn:

(1) For the region of atrophic posterior maxilla, the choice of maxillary sinus augmentation approaches was determined by its residual bone volume and bone quality

(2) Graft could optimize stress distribution in supporting bone and its load-bearing capability was largely depended on the stiffness

\section{Data Availability}

The data used to support the findings of this study are available from the corresponding author upon request.

\section{Conflicts of Interest}

The authors declare no competing interests.

\section{Authors' Contributions}

X. Wang, T.Q. Zhang, and E.L. Yang conceived the general idea and framework of the project, analyzed and interpreted the data, and oversaw the project to its completion. H.W. Wu and D.S. Zhang designed the overall research. H.Z. Shen contributed to data collection. All the authors discussed the results and reviewed the manuscript. Xuan Wang, Tianqi Zhang, and Enli Yang contributed equally to this work.

\section{Acknowledgments}

Thanks are due to Professor Guangchun Wang of the school of materials science and engineering of Shandong University for his excellent technical assistance. This study is supported by the National Natural Science Foundation of China (grant number 81901022).

\section{References}

[1] B. E. Pjetursson, K. Tan, N. P. Lang, U. Bragger, M. Egger, and M. Zwahlen, "A systematic review of the survival and complication rates of fixed partial dentures (FPDs) after an observation period of at least 5 years. I. Implant-supported FPDs," Clinical Oral Implants Research, vol. 15, no. 6, pp. 625-642, 2004.

[2] O. L. Koca, G. Eskitascioglu, and A. Usumez, "Three-dimensional finite-element analysis of functional stresses in different bone locations produced by implants placed in the maxillary posterior region of the sinus floor," The Journal of Prosthetic Dentistry, vol. 93, no. 1, pp. 38-44, 2005.
[3] H.-G. Yoon, S.-J. Heo, J.-Y. Koak, S.-K. Kim, and S.-Y. Lee, "Effect of bone quality and implant surgical technique on implant stability quotient (ISQ) value," J Adv Prosthodont, vol. 3, no. 1, pp. 10-15, 2011.

[4] S. H. Chang, C. L. Lin, Y. S. Lin, S. S. Hsue, and S. R. Huang, "Biomechanical comparison of a single short and wide implant with monocortical or bicortical engagement in the atrophic posterior maxilla and a long implant in the augmented sinus," The International Journal of Oral \& Maxillofacial Implants, vol. 27, no. 6, pp. 1594-1594, 2012.

[5] D. Busenlechner, C. D. Huber, C. Vasak, A. Dobsak, R. Gruber, and G. Watzek, "Sinus augmentation analysis revised: the gradient of graft consolidation," Clinical Oral Implants Research, vol. 20, no. 10, pp. 1078-1083, 2009.

[6] A. M. Price, M. Nunn, F. G. Oppenheim, and T. E. Van Dyke, "De novo bone formation after the sinus lift procedure," Journal of Periodontology, vol. 82, no. 9, pp. 12451255, 2011.

[7] M. Del Fabbro, T. Testori, L. Francetti, and R. Weinstein, "Systematic review of survival rates for implants placed in the grafted maxillary sinus," The International Journal of Periodontics \& Restorative Dentistry, vol. 24, no. 6, pp. 565-577, 2004.

[8] L. A. A. Zorzano, M. J. R. Tojo, and J. M. A. Urizar, "Maxillary sinus lift with intraoral autologous bone and B-tricalcium phosphate: histological and histomorphometric clinical study," Medicina Oral, Patología Oral y Cirugía Bucal, vol. 12, no. 7, pp. E532-E536, 2007.

[9] A. A. Winter, A. S. Pollack, and R. B. Odrich, "Placement of implants in the severely atrophic posterior maxilla using localized management of the sinus floor: a preliminary study," The International Journal of Oral \& Maxillofacial Implants, vol. 17, no. 5, pp. 687-695, 2002.

[10] A. A. Winter, A. S. Pollack, and R. B. Odrich, "Sinus/alveolar crest tenting (SACT): a new technique for implant placement in atrophic maxillary ridges without bone grafts or membranes," The International Journal of Periodontics \& Restorative Dentistry, vol. 23, no. 6, pp. 557-565, 2003.

[11] J. Merheb, N. Nurdin, M. Bischof, M. Gimeno-Rico, M. Quirynen, and R. Nedir, "Stability evaluation of implants placed in the atrophic maxilla using osteotome sinus floor elevation with and without bone grafting: A 5-year prospective study," The International Journal of Oral Implantology, vol. 12, no. 3, pp. 337-346, 2019.

[12] V. C. Palma, O. Magro-Filho, J. A. de Oliveria, S. Lundgren, L. A. Salata, and L. Sennerby, "Bone reformation and implant integration following maxillary sinus membrane elevation: an experimental study in primates," Clinical Implant Dentistry and Related Research, vol. 8, no. 1, pp. 11-24, 2006.

[13] H. Aludden, A. Mordenfeld, M. Hallman, A. E. Christensen, and T. Starch-Jensen, "Osteotome-mediated sinus floor elevation with or without a grafting material: a systematic review and meta-analysis of long-term studies ( $\geq 5$-years)," Implant Dentistry, vol. 27, no. 4, pp. 488-497, 2018.

[14] D. L. Cochran, "The scientific basis for and clinical experiences with Straumann implants including the ITI ${ }^{\circledR}$ Dental Implant System: a consensus report," Clinical Oral Implants Research, vol. 11, pp. 33-58, 2000.

[15] V. Demenko, I. Linetsky, V. Nesvit, L. Linetska, and A. Shevchenko, "FE study of bone quality effect on loadcarrying ability of dental implants," Computer Methods in 
Biomechanics and Biomedical Engineering, vol. 17, no. 16, pp. 1751-1761, 2013.

[16] M. Sevimay, F. Turhan, M. A. Kilicarslan, and G. Eskitascioglu, "Three-dimensional finite element analysis of the effect of different bone quality on stress distribution in an implantsupported crown," The Journal of Prosthetic Dentistry, vol. 93, no. 3, pp. 227-234, 2005.

[17] X. Yan, X. Zhang, J. Gao et al., "Maxillary sinus augmentation without grafting material with simultaneous implant installation: a three-dimensional finite element analysis," Clinical Implant Dentistry and Related Research, vol. 17, no. 3, pp. 515-524, 2015.

[18] J. P. Geng, K. B. C. Tan, and G. R. Liu, “Application of finite element analysis in implant dentistry: a review of the literature," The Journal of Prosthetic Dentistry, vol. 85, no. 6, pp. 585-598, 2001.

[19] M. I. Fanuscu, H. V. Vu, and B. Poncelet, "Implant biomechanics in grafted sinus: a finite element analysis," The Journal of Oral Implantology, vol. 30, no. 2, pp. 59-68, 2004.

[20] U. Lekholm, G. A. Zarb, and T. Albrektsson, "Patient selection and preparation," in Tissue integrated prostheses, pp. 199-209, Quintessence, Chicago, 1985.

[21] G. Tepper, R. Haas, W. Zechner, W. Krach, and G. Watzek, "Three-dimensional finite element analysis of implant stability in the atrophic posterior maxilla - a mathematical study of the sinus floor augmentation," Clinical Oral Implants Research, vol. 13, no. 6, pp. 657-665, 2002.

[22] L. Baggi, I. Cappelloni, M. Di Girolamo, F. Maceri, and G. Vairo, "The influence of implant diameter and length on stress distribution of osseointegrated implants related to crestal bone geometry: a three-dimensional finite element analysis," The Journal of Prosthetic Dentistry, vol. 100, no. 6, pp. 422-431, 2008.

[23] T. Li, X. Yang, D. Zhang et al., "Analysis of the biomechanical feasibility of a wide implant in moderately atrophic maxillary sinus region with finite element method," Oral Surgery, Oral Medicine, Oral Pathology, Oral Radiology, vol. 114, no. 2, pp. E1-E8, 2012.

[24] S. H. Chang, C. L. Lin, S. S. Hsue, Y. S. Lin, and S. R. Huang, "Biomechanical analysis of the effects of implant diameter and bone quality in short implants placed in the atrophic posterior maxilla," Medical Engineering \& Physics, vol. 34, no. 2, pp. 153-160, 2012.

[25] D. Lin, Q. Li, W. Li, N. Duckmanton, and M. Swain, "Mandibular bone remodeling induced by dental implant," Journal of Biomechanics, vol. 43, no. 2, pp. 287-293, 2010.

[26] E. Erkmen, G. Meric, A. Kurt, Y. Tunc, and A. Eser, "Biomechanical comparison of implant retained fixed partial dentures with fiber reinforced composite versus conventional metal frameworks: a 3D FEA study," Journal of the Mechanical Behavior of Biomedical Materials, vol. 4, no. 1, pp. 107-116, 2011.

[27] D. Lin, Q. Li, W. Li, and M. Swain, "Dental implant induced bone remodeling and associated algorithms," Journal of the Mechanical Behavior of Biomedical Materials, vol. 2, no. 5, pp. 410-432, 2009.

[28] I. C. Chou, S. Y. Lee, M. C. Wu, C. W. Sun, and C. P. Jiang, "Finite element modelling of implant designs and cortical bone thickness on stress distribution in maxillary type IV bone," Computer Methods in Biomechanics and Biomedical Engineering, vol. 17, no. 5, pp. 516-526, 2012.
[29] J.-S. Lee, I.-H. Cho, Y.-S. Kim, S.-J. Heo, H.-B. Kwon, and Y.J. Lim, "Bone-implant interface with simulated insertion stress around an immediately loaded dental implant in the anterior maxilla: a three-dimensional finite element analysis," The International Journal of Oral \& Maxillofacial Implants, vol. 27, no. 2, pp. 295-302, 2012.

[30] S. Inglam, S. Suebnukarn, W. Tharanon, T. Apatananon, and K. Sitthiseripratip, "Influence of graft quality and marginal bone loss on implants placed in maxillary grafted sinus: a finite element study," Medical \& Biological Engineering \& Computing, vol. 48, no. 7, pp. 681-689, 2010.

[31] D. van Steenberghe, B. Klinge, U. Linden, M. Quirynen, I. Herrmann, and C. Garpland, "Periodontal indices around natural and titanium abutments: a longitudinal multicenter study," Journal of Periodontology, vol. 64, no. 6, pp. 538-541, 1993.

[32] B.-K. Lee, "One-stage operation of large oroantral fistula closure, sinus lifting, and autogenous bone grafting for dental implant installation," Oral Surgery, Oral Medicine, Oral Pathology, Oral Radiology, and Endodontics, vol. 105, no. 6, pp. 707-713, 2008.

[33] X. U. YAN, X. I. N. W. E. N. ZHANG, W. E. I. C. H. A. O. CHI, H. O. N. G. J. U. N. AI, and L. I. N. WU, “Association between implant apex and sinus floor in posterior maxilla dental implantation: A three-dimensional finite element analysis," Experimental and Therapeutic Medicine, vol. 9, no. 3, pp. 868-876, 2015.

[34] G. Arun Kumar, B. Mahesh, and D. George, "Three dimensional finite element analysis of stress distribution around implant with straight and angled abutments in different bone qualities," J Indian Prosthodont Soc, vol. 13, no. 4, pp. 466472, 2013.

[35] H. L. Huang, L. J. Fuh, J. T. Hsu, M. G. Tu, Y. W. Shen, and C. L. Wu, "Effects of implant surface roughness and stiffness of grafted bone on an immediately loaded maxillary implant: a 3D numerical analysis," Journal of Oral Rehabilitation, vol. 35, no. 4, pp. 283-290, 2008.

[36] J. Y. K. Kan, K. Rungcharassaeng, J. Kim, J. L. Lozada, and C. J. Goodacre, "Factors affecting the survival of implants placed in grafted maxillary sinuses: a clinical report," The Journal of Prosthetic Dentistry, vol. 87, no. 5, pp. 485-489, 2002.

[37] S. Taschieri, S. Corbella, M. Saita, I. Tsesis, and M. Del Fabbro, "Osteotome-Mediated Sinus Lift without Grafting Material: A Review of Literature and a Technique Proposal," International Journal of Dentistry, vol. 2012, Article ID 849093, 9 pages, 2012.

[38] F. Duttenhoefer, C. Souren, D. Menne, D. Emmerich, R. Schön, and S. Sauerbier, "Long-Term Survival of Dental Implants Placed in the Grafted Maxillary Sinus: Systematic Review and Meta-Analysis of Treatment Modalities," PLoS ONE, vol. 8, no. 9, p. e75357, 2013.

[39] M. Esposito, M. G. Grusovin, J. Rees et al., "Effectiveness of sinus lift procedures for dental implant rehabilitation: a Cochrane systematic review," European Journal of Oral Implantology, vol. 3, no. 1, pp. 7-26, 2010.

[40] J. Cabezas-Mojon, C. Barona-Dorado, G. Gomez-Moreno, F. Fernandez-Caliz, and J. M. Martinez-Gonzalez, "Meta-Analytic Study of Implant Survival Following Sinus Augmentation," Medicina Oral Patología Oral y Cirugia Bucal, vol. 17, no. 1, pp. E135-e139, 2012. 
[41] M. Del Fabbro, S. Corbella, T. Weinstein, V. Ceresoli, and S. Taschieri, "Implant survival rates after osteotomemediated maxillary sinus augmentation: a systematic review," Clinical Implant Dentistry And Related Research., vol. 14, pp. e159-e168, 2012.

[42] G. B. Bruschi, A. Scipioni, G. Calesini, and E. Bruschi, "Localized management of sinus floor with simultaneous implant placement: a clinical report," The International Journal of Oral \& Maxillofacial Implants, vol. 13, no. 2, pp. 219-226, 1998. 